\title{
Topographic mapping in the National Spatial Data Infrastructure in Ukraine
}

\author{
Yurii Karpinskyi ${ }^{1}$, Nadiia Lazorenko-Hevel $^{2 *}$ \\ ${ }^{1}$ Department of Geoinformation system and photogrammetry, Kyiv National University of Construction and Architecture, 31 \\ Povitroflotsky Ave, 03037, Kyiv, Ukraine, orcid.org/0000-0002-0701-1277 \\ ${ }^{2}$ Department of Geoinformation system and photogrammetry, Kyiv National University of Construction and Architecture, 31 \\ Povitroflotsky Ave, 03037, Kyiv, Ukraine, orcid.org/0000-0002-1572-4947
}

\begin{abstract}
The article proposes a new development concept of topographic mapping in Ukraine. It is based on the implementation of a new system model that responds to the geoinformation approach to topographic mapping in the development of national geospatial data infrastructure (NSDI) and provides the creation of geospatial data sets in the form of databases and knowledge bases based on existing standards and specifications: series of international standards ISO 19100 "Geographic information/Geomatics", Open Geospatial Consortium (OGS), INSPIRE, State Standards of Ukraine (DSTU), Complex of Standards Organization of Ukraine (SOU) "Topographic database". It provides a high intellectual level of core reference and profile geospatial data, which is capable to provide geoinformation analysis and modeling in modern GIS. In addition, the implementation the infrastructure approach to topographic production and the creation and development of a permanent topographic monitoring system will ensure the publication of geospatial data in real time, almost simultaneously with changes in the terrain, which guarantees the maintenance of a single topographic basis and, accordingly, core reference datasets for NSDI. Publication is funded by the Polish National Agency for Academic Exchange under the International Academic Partnerships Programme from the project „Organization of the 9th International Scientific and Technical Conference entitled Environmental Engineering, Photogrammetry, Geoinformatics - Modern Technologies and Development Perspectives".
\end{abstract}

\section{Introduction}

Recently, the powerful system of topographic mapping of the terrain was created in the Soviet Union as part of the mapping production infrastructure. In a comparatively short time, practically the entire territory of Ukraine was covered by topographic maps on a scale of 1:10 000, which was approximately 30000 map sheets, with up to 3000 of them was updated annually.

The lifecycle of the creation (updating) topographic maps was approximately 2 years. Besides in the Soviet Union the consistency was introduced for the main content elements between adjacent scale sheets, where topographic maps of the scale 1: 25000 was based on the scale of 1:10 000, maps of 1:50 000 was based on sheets 1:25 000 and so on. The quality of these maps, the accuracy, detail, information and clarity were so high that they made it a world reference sample [6]. At the same time, the information content, the catalogue of topographic features and their characteristics were clearly military-oriented [9]. The "Soviet" stage of topographic mapping development ended with the digital mapping development and the first use of geoinformation systems.
However, in most cases geoinformation resources in the public sector are created on the departmental basis without a coherent technological policy, without uniform methodological principles and technical regulations. Collection processes, requirements for the structure, composition and quality of geospatial data are not coordinated, data are recorded using different mapping sources, in different classification systems, and using different software and technology tools.

Such uncoordinated activity fatally leads to inconsistency of information flows and duplication costly and time-consuming topographic-geodetic and cartographic works on data capturing and creation, and ultimately to increase costs while reducing the quality and value of information as a basis for the functioning of information support systems.

For the period 1992-2019 in Ukraine at the state level laws and decrees were adopted on the maintenance of separate state cadastres, in particular: land, urban, forest, water, mineral deposits and manifestations, natural territories of resorts, natural healing resources, territories and natural resources of nature reserve fund, flora and fauna etc.

\footnotetext{
Corresponding author: lazorenko-gevel.niu@knuba.edu.ua, nadinlu@ukr.net
} 
Cartographic and cadastral activities in Ukraine are carried out with a lack of cooperation between different agencies and, often, competition between different institutions in cadastre matters and, as a result, without coordination and without a well-defined national concept of cadastre development.

Sectoral cadastres are organized and functionally separated. The level and forms of financial, regulatory, methodological, information and technological support of sectoral cadastres are very different.

This has led to the simultaneous action of various departmental "mandates": regulations, sectoral regulations, departmental orders, temporary instructions, techniques, etc. during the collection, registration and use of information in different cadastral systems. All these and other problems are solved by developing the national geospatial data infrastructure.

Considering the above issues, in the regulatory support of topographic-geodetic and cartographic industry there were important changes related to the introduction of amendments to the Law of Ukraine "On topographicgeodetic and cartographic activity", where the main purpose of topographic-geodetic activity was determined by the development of national geospatial data infrastructure, and approval Resolution of the Cabinet of Ministers of Ukraine "On Approval of the Procedure of National Topographic and Thematic Mapping" of September 4, 2013 No. 661, according to which topographic and thematic maps acquired whether the status of state. The acquisition of such status of topographic and thematic maps requires a significant increase in their information and technological level.

As collecting and processing geospatial data is a very costly process, both financially and temporally, it would be logical to keep the following rule: "Geospatial data that has been collected must be used repeatedly and by different users". This multiple use of geospatial data can only be achieved under conditions of creation and development of national geospatial data infrastructure.

\section{Goal of a research}

The current condition of decision-making on territorial development and spatial planning requires inter-sectoral integration of geospatial data, which causes the transition from mapping production infrastructure to the development of geospatial data infrastructures. As the costs value of territorial management decisions is increasing, the requirements for Core Reference Dataset (CRD) are growing too, because $\mathrm{CRD}$ is the only topographic basis for integrating all profile datasets.

Such an increase the value of the topographic basis, in addition to the traditional requirements, such as: relevance, reliability, accuracy, detail, informativeness, clarity, requires additional requirements to increase the intellectual level of the Core Reference Dataset, which would correspond to the modern development level of geoinformation systems and fully provide geospatial analysis and modelling, data interoperability, and the ability to integrate data from different sources. In addition, current requirements for the CRD require the development of a permanent system for monitoring and updating them $[3,4$, 5].

Analysing the list of the Core Reference Data, we can conclude that they constitute the majority of features of the real world - the topographic features, which in turn increases the importance of topographic mapping in the conditions of development of NSDI.

\section{Methodology and scope of a research}

The basis for the research is the analysis of the possibilities of applying the theory of databases and knowledge bases which should be created on the basis of the use of a series of international standards ISO 19100 "Geographic Information /Geomatics", Open Geospatial Consortium (OGC) and INSPIRE for solving problems of improving the intellectual level of Core Reference Datasets of geospatial data $[1,2,4]$.

The research is related to the implementation of the Ukrainian-Japanese project "Creation the National Geospatial Data Infrastructure in Ukraine" (2015-2018) and of the Ukrainian-Norwegian project "Maps for good land governance", aimed at creating a unified digital topographic basis M 1: 50000 for the whole territory of Ukraine.

\section{The current state of geoinformation services in Ukraine}

Currently, there are 13 types of state cadastres in Ukraine such as: land, urban, water, forest, mineral deposits and manifestations, natural healing resources, territories and objects of nature reserve fund, natural territories of resorts, cadastres of wildlife and flora, radioactive waste repositories, aquatic bioresources and fisheries water bodies and a national inventory of anthropogenic emissions and greenhouse gas absorption. All of them require up-to-data and high-quality Core Reference Datasets in the form of topographic maps and plans. In 2018, an analysis of topographic and geodetic and geoinformation works was carried out using tender materials to determine the demand for topographic and geodetic works and cartographic products in Ukraine. Public procurement information obtained from tender platforms was used as an indicator of demand for topographic and geodetic works and mapping products and to identify their areas of application. 64 tenders for the period 2016-2018 were considered. In percentage terms, the division of tenders into official categories was determined: scientific and technical services in the engineering field make up 28\%; architectural, engineering and surveying services $-14 \%$; software related services $-11 \%$; information systems $-6 \% ; 5 \%$ are: complex engineering services, data processing services, digital mapping and other services account for $26 \%$.

According to the categories of tenders, their distribution by purpose was determined: most were orders for creation (updating) of topographic plans of territories of cities and settlements -24 , software for work with geospatial data of urban planning cadastre -8 , creation of topographic basis for urban planning documentation -6 , software providing for work with other profile geospatial data, etc. (Fig. 2). In addition, topographic plans of the scale 1: 2000 and the 
smallest 1: 5000 were found to be in greatest demand. In addition, 3 tenders concerned the creation of topographic maps of the scale 1: 10000, 1: 25000, 1: 100000 for the territory of cities and southern regions of Ukraine for military purposes.

The purpose of the article is to research whether digital topographic maps can be a Core Reference Dataset for the creation and development of the National Geospatial Data Infrastructure; substantiation of the basic principles of topographic mapping in the context of the NSDI development in Ukraine and the new system model that describes the geoinformation approach to topographic mapping in the NSDI and takes into account the importance of creating and development of topographic monitoring of the terrain, and also solves the issues of multiple use of geospatial databases.

\section{Topographic mapping $K_{m}$ the mapping production infrastructure}

The cartographic approach to the production of digital topographic maps and plans can be described as a system model as the interaction of three following systems: a terrain $T$ containing a set of mapped features; a set of topographic information $I$ obtained as a result of topographic survey $f_{T I}$, and a digital map $M$ formed as a result of the processing of topographic information in the environment of geographic information systems $f_{I M}$ (Fig. 1) [7].

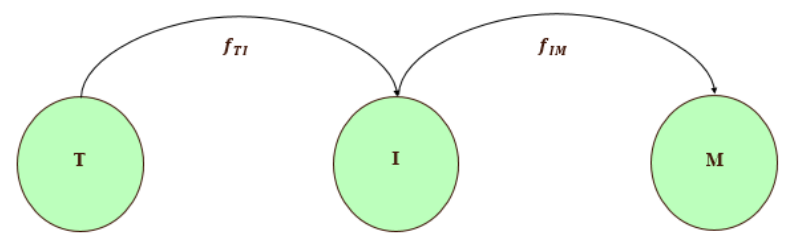

Fig. 1. The system model of the cartographic approach to the production of digital topographic maps and plans

$$
K_{m}=\{T, I, M, F\}
$$

where $K_{m}$ - topographic mapping in the infrastructure of cartographic production;

$T$ - the feature set that are mapped while performing a series of topographic survey work $f_{T I}$;

$I$ - the set of topographic information $f_{T I}: T \rightarrow I, f_{T I} \in F$;

$f_{I M}$ - the digital map creation in the geographic information systems environment, using the mapping methods $f_{I M}: I$ $\rightarrow M, f_{I M} \in F$;

$M$ - digital map.

Currently, the main trends in the development of topographic-geodetic and mapping activities are dependent to the development of information technologies, in particular, global navigation satellite systems (GNSS) location of features, aerospace high-resolution systems to capture information about the Earth, the creation of highperformance facilities of capturing spatial information about Earth in real time based on optical-electronic terrain scanning systems, satellite radar, laser scanning, digital aerial photography including drones, non-metric cameras, pictographic capture to creation of realistic terrain models, digital imaging and geospatial information, the widespread use of geoinformation systems and telecommunication technologies as a primary facility of providing access to geospatial data and information etc. (Kent D. Lee, 2013). The lifecycle of creation (updating) topographic maps has been reduced to 3-6 months. Digital terrain maps are created in the environment of modern geoinformation systems (GIS): ArcGIS, QGIS, GeoMedia and more. Such maps are made for a specific customer and he uses them only for his own needs. That is, the map is made once for a specific customer to perform specific tasks.

With this approach, the digital map is the "cut of the terrain" compiled at a certain time and does not take into account changes in the terrain. In addition, during topographic surveys, as a rule, only topographic characteristics of geospatial features are collected and data from different sources are not integrated. The production of a digital map occurs in the context of a specific GIS that does not provide the interoperability of geospatial data collected in other GIS, causes problems in creating, updating, exchanging sharing and distributing such data between different producers and users.

The exchange of geoinformation models between GIS of different producers happens using data converters. It is easy to identify the main disadvantages of corporate GIS with such an architecture. Besides the process of converting large amounts of data becomes into a time-consuming process, the converted data, as a rule, does not fully reflect the original structure of the source geoinformation model. This, in turn, requires the additional cost of adjusting the result model conversion, and in general there is duplication of information in different GIS formats, practically - the integrity and adequacy of data models are not exactly ensured, and data management is difficult $[12,13]$.

In view of the above, the answer to the question whether digital topographic maps in the file structures form can be a core reference data for the creation and development of national geospatial data infrastructure is obvious: neither can they, because the main condition for the creation and development of NSDI is the interoperability of geospatial data for creation, integration from different sources, updating, sharing, distribution between different producers and users.

\section{Topographic mapping $K_{D}$ in the geospatial data infrastructure}

The new system model is proposed that describes the geoinformation approach to topographic mapping in the geospatial data infrastructure.

This dynamic model consists of four systems: $T$ - terrain with numerous simulated geospatial features; $I$ - set of topographic information obtained as a result of topographic and geodetic and cartographic works using methods of geospatial data collection $f_{T I} ; D$ - a bank of topographic data that forms the basis of topographic data $f_{I D}$ and $M$ - sets of digital topographic maps that are formed during the queries executions $f_{D M}$ to the bank of topographic data. In addition, the model takes into account changes in the terrain $-f_{T T}$, these changes are made during the updating the set of 
topographic information $-f_{I I}$, thereafter the process of updating the bank of topographic data $-f_{D D}$ takes place and accordingly there is an opportunity to update the set of digital maps $-f_{M M}$ (Fig.2).

$$
K_{D}=\{T, I, D, M, F\}
$$

where:

$K_{D}$ - topographic mapping in the geospatial data infrastructure;

I - set of topographic information: $F: T \rightarrow M$,

$F=\left\{f_{T T}, f_{T I}, f_{I I}, f_{I D}, f_{D D}, f_{D M}, f_{M M}\right\}$

$D$ - topographic data bank;

$M$ - topographic maps;

$f_{T T}$ - the process of changing the terrain: $f_{T T}: T \rightarrow$ $T, f_{T T} \in F$

$f_{T I}$ - the complex of works on topographic surveying: $f_{T I}: T \rightarrow T, f_{T I} \in I$

$f_{I I}-$ updating the set of topographic information: $f_{I I}: I \rightarrow$ $I, f_{I I} \in F$

$f_{I D}$ - creation of the topographic data base - Clearing House: $f_{I D}: I \rightarrow D, f_{I D} \in F$

$f_{D D}$ - updating of the topographic data base: $f_{D D}: D \rightarrow$ $D, f_{D D} \in F$

$f_{D M}$ - creation the set of digital topographic maps: $f_{D M}: D \rightarrow M, f_{D M} \in F$

$f_{M M}$ - updating the set of digital topographic maps: $f_{M M}: M \rightarrow M, f_{M M} \in F$

It is the whole set of processes $F: f_{T T}, f_{T I}, f_{I I}, f_{I D}, f_{D D}, f_{D M}, f_{M M}$, - that actually make up topographic monitoring of the terrain:

$$
F=\left\{f_{T T}, f_{T I}, f_{I I}, f_{I D}, f_{D D}, f_{D M}, f_{M M}\right\}
$$

To the traditional components of the system model of the topographic mapping system, a topographic data base (TDB) is added, which becomes the core of topographic mapping. Such a database allows you to create a set of topographic maps that are formed during the execution of requests to the TDB. At the same time, the model takes into account changes in the terrain, these changes in the terrain are introduced during the updating of the set of topographic information; further there is a process of updating the bank of topographic data and, accordingly, there is the possibility of updating the set of digital maps.

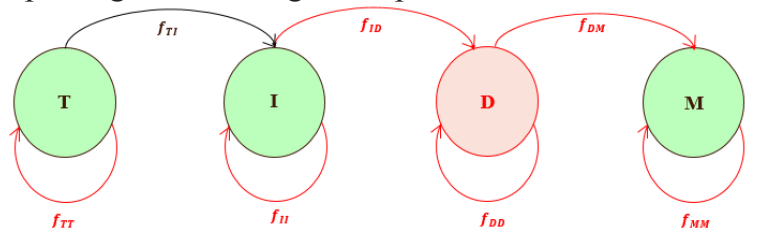

Fig. 2. The system model of the geoinformation approach to topographic mapping in the geospatial data infrastructure

The architecture of the main state topographic map (Fig. 3), which corresponds to the geoinformation approach to topographic mapping under the conditions of development of the national infrastructure of geospatial data, can be described as follows:

1. We have a terrain $(T)$ with a constantly changing and time-varying geospatial features $-f_{T T}$;

2. A number of topographic information obtained as a result of topographic, geodetic and mapping works using methods of geospatial data collection $f_{T T}$. The latter include the following methods: contact, remote, mapping, open source and crowdsourcing-technologies, and combined ones [5]. Terrain changes are made when updating the set of topographic information $-f_{I I}$.

3. The topographic data bank $D$, which is formed by distributed of topographic databases $-f_{I D}$, DBMS and GIS tools. Distributed of topographic databases are based on accepted national UML models developed on the basis of international and state standards and specifications in the field of Geographic Information/Geomatics. The information concerning changes in the area is updated in TDB in real time [8, 10, 11].

4. Digital topographic maps $M$ are formed as a result of requests to the topographic data bank $-f_{D M}$. The constant updating of information in the bank of topographic data provides updating of a set of digital maps $-f_{M M}$ and conducting of topographic monitoring of the area.

5. Increasing the level of access to the main state topographic map (MSTM) is provided by the MSTM geoportal and following services:

- search services that provide the detection of geospatial data and geospatial data services in information networks;

- services for viewing geospatial data, information on characteristics of geospatial features and content of metadata;

- access services providing direct access to geospatial data or obtaining copies of them;

- coordinate operations services that provide the transformation and turning coordinates of geospatial data from one coordinate system or map projection into another one.

6. On the basis of the information received from the geoportal of the main state topographic map, producers create their geographic information products: WEB applications, GIS applications, profile SDB's and GIS. The geoinformation approach to topographic mapping in the national geospatial data infrastructure is based on the following principles:

- Topographic monitoring of the territories;

- The topographic database is the core of topographic mapping. The topographic database should not depend on GIS software;

- Creation of digital topographic maps;

- Increasing the intellectual level of geospatial data creation;

- Integration of topographic and profile data.

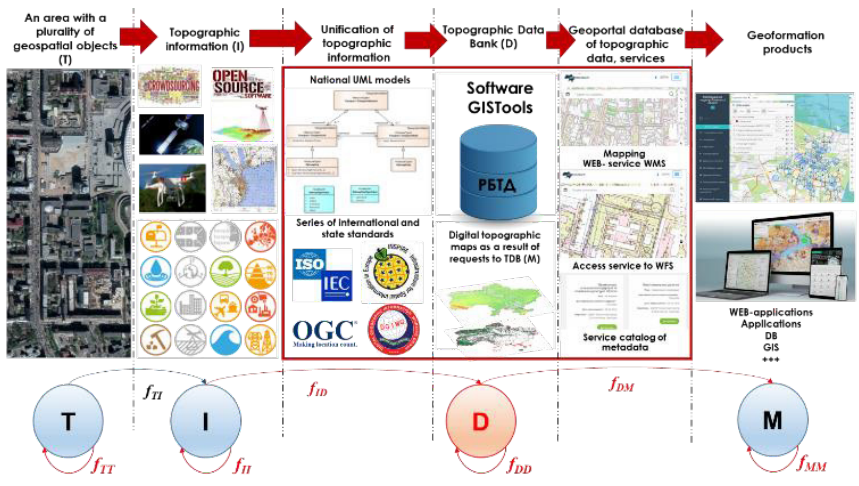


Fig. 3. The architecture of topographic mapping in NSDI

\section{Conclusions}

The article explores two approaches to the production of digital topographic maps and plans: mapping and geoinformation.

It has been found that the mapping approach to the creation (updating) of digital topographic maps no longer satisfies the modern industries and society, since in this approach the digital map is a "slice of the terrain" for a certain period of time and does not take into account the changes of the terrain, does not allow for data integration, collected from different sources for map updating and digital map production occurs in a specific GIS environment, which does not ensure the interoperability of geospatial data collected in other GIS, causing problems with creating, updating, exchange and sharing of information between producers and users.

It has also been found that digital topographic maps in the form of file structures cannot be the Core Reference Dataset, but may be in the case of creation (updating) them as datasets within the topographic database.

In the architecture of modern GIS, which by the evolution of geoinformation systems belong to the third generation GIS, is observed their complete integration with universal DBMS, as well as their access to the global information space via the Internet.

In such GIS, both components of the geographic feature model (attribute and spatial) are stored in a single database environment, and the extended SQL language allows you to describe many spatial predicates to perform spatial analysis.

Therefore, a new system model is proposed, which corresponds to the geoinformation approach to topographic mapping in the context of development of national geospatial data infrastructure and provides for the creation of geospatial data sets in the form of databases and knowledge bases.

Providing of an infrastructure approach to topographic production and the creation and development of a permanent topographic monitoring system will ensure the publication of geospatial data in real time, almost simultaneously with changes in the terrain, which guarantees the maintenance of a single topographic base and, accordingly, Core Reference Dataset for NSDI.

Organization of such databases in accordance with standards and specifications: series of international standards ISO 19100 “Geographic Information/Geomatics", Open Geospatial Consortium (OGS), INSPIRE, State Standards of Ukraine (DSTU), Complex of Standards of Organization of Ukraine (SOU) "Topographic Database" provides them with a high intellectual level, capable of providing geoinformation analysis and modeling in modern GIS.

It is geospatial databases can integrate data from different relational models based on Union (Join) operation. Also, the use of distributed of topographic databases will ensure the independence of geospatial data from any GIS that restrict the use and exchange of data between different manufacturers and users of geospatial data.
Also, the use of distributed of topographic databases will ensure the independence of geospatial data from any GIS that restrict the use and exchange of data between different producers and users of geospatial data.

\section{Acknowledgments}

The authors would like to thank the Sendzimir Foundation for sharing their knowledge and experience in the field of construction of rain gardens and for highly substantive care during student internship.

Publication is funded by the Polish National Agency for Academic Exchange under the International Academic Partnerships Programme from the project „Organization of the $9^{\text {th }}$ International Scientific and Technical Conference entitled Environmental Engineering, Photogrammetry, Geoinformatics - Modern Technologies and Development Perspectives".

\section{References}

1. Yu. O. Karpinskyi, A. A. Lyashchenko, Yasuyuki Okada. Structure and principles development of national profile standards of geographic information 129. Retrieved from http://geojournal.xyz/documents/63 journal.pdf (2016)

2. Yu. O. Karpinskyi, N. Lazorenko-Hevel. Application of topographic plans in the conditions of the development of national spatial data infrastructure Retrieved from http://nbuv.gov.ua/UJRN/MTP $201868 \quad 85$ (2018)

3. Yu. Karpinsky, A. A. LyashchenkoStrategy of National Spatial Data Infrastructure forming in Ukraine K.: RIGC, 2006. - 108.: pic. - (Ser. "Geodesy, Cartography, Cadastre") (2006)

4. Yu. Karpinsky, A. A. Lyashchenko, R. V. Runec. Reference model of topographic database Retrieved from http://nbuv.gov.ua/UJRN/vgtk_2010 2 9 (2010)

5. Yu. Karpinsky, N. Lazorenko-Hevel. The methods of geospatial data collection for topographic mapping Retrieved from http://gki.com.ua/ua/metodi-zbirannjageoprostorovih-danih-dlja-topografichnogo-

kartografuvannja (2018)

6. Kent D. Lee. Russian data illuminate world mapping. Imaging notes. Retrieved from http://gislab.info/docs/russian-topo.pdf (2003)

7. D. B Lisitskyi. System analysis of ground topographic survey methods. - System research in geodesy. Interuniversity collection. - Novosibirsk. - 1984. - p. 76-84 (1984)

8. Siyuan Lu, Xiaoyan Shao, Marcus Freitag, Levente J. Klein, Jason Renwick, Fernando J. Marianno, Conrad Albrecht, Hendrik F. Hamann. IBM PAIRS Curated Big Data Service for Accelerated Geospatial Data Analytics and Discovery. 2016 IEEE International Conference on Big Data (Big Data). Retrieved from https://static.aminer.org/pdf/fa/bigdata2016/S09208.pdf (2016)

9. R. I. Sossa. (2003) Topographic cartography of the territory of Ukraine (b. 1920 - 2002): Bibliogr. show / R. I. 
Sossa. - K.: DNVP Kartografiya. 127 (Ser. Ukr. Map: history, country, prospects) (2003)

10. The national standard of Ukraine DSTU 8774: 2018

"Geographical information. Geospatial data modeling rules" Retrieved from http://gki.com.ua/ua/prinjatonacionalni-standart-ukraiini-dstu-87742018-geografichnainformacija-pravila-modeljuvannja-geoprostorovih-danih 11. Frank. Requirements for a database management system for a GIS, Photogrammetric Eng. \& Remote Sensing, vol. 54, no. II, pp. 1557-1564, Nov. 1988. Retrieved from

https://www.asprs.org/wpcontent/uploads/pers/1988journal/ nov/1988 nov 1557-1564.pdf (1988)

12. Lyashchenko A. A., Cherin A. G. Architecture of modern GIS based on geospatial data bases Retrieved from https://softpro.ua/arhitektura-suchasnih-gis-na-osnovi-bazgeoprostorovih-danih (2011)

13. Lyashchenko A.A. Conceptual modeling of geoinformation systems. - Bulletin of geodesy and cartography. - № 4. - P. 44-50 (2002) 